\title{
Presentación del Dossier
}

Dossier Revisando la Biblia desde perspectivas modernas. En los espacios de fe, el texto bíblico ocupa un espacio privilegiado y fundacional y, dadas las innumerables posibilidades hermenéuticas, acaba teniendo variadas implicaciones. Lo mismo ocurre en el mundo de la investigación en las áreas de historia, arqueología, sociología, literatura; en este universo, el texto bíblico ha ganado atención en los últimos años.

El texto bíblico, polisémico, abre infinitos caminos, inicialmente señalados y marcados por la institución religiosa y en las últimas décadas ha ido adquiriendo nuevos aires, nuevas miradas, nuevos supuestos que han dado lugar a respuestas sorprendentes que dan tonalidades caleidoscópicas al texto bíblico canonizado; haciendo que el texto sea nuevo. Esto se debe a la búsqueda de textos y contextos, por parte de investigadores e investigadores, que buscan nuevos significados, nuevas pertenencias, nuevas respuestas.

Los textos canónicos y extracanónicos vuelven a ser visitados desde la perspectiva de la antropología, la geografía, la iconografía, el cine y muchas otras. Literatura que se reforma cuando se revisa bajo perspectivas modernas, que pervierten, invierten y nos ofrecen nuevos caminos hermenéuticos.

Un primer bloque de artículos nos muestra el diálogo con la literatura, el cine y el arte en la perspectiva de la elaboración de significados. Esto es lo que nos presentan los investigadores e investigadores de este Dossier. Un breve compendio de posibilidades.

Para ello, Luana Martins Golin demuestra las características literarias de la Biblia y su importancia en el diálogo con la cultura y otras literaturas, allanando el camino para las polisemias y diversas propuestas hermenéuticas que vendrán a continuación. Paulo Augusto de Souza Nogueira, nos presentan la recreación de la Biblia bajo las luces del cine, a través de la película Metrópolis; señalando las implicaciones de transformar texto en imagen en movimiento. Marcelo da Silva Carneiro busca en las experiencias religiosas del protocristianismo, como la magia, el exorcismo, los viajes celestiales y la glosolalia, indicar una forma de superar el racionalismo académico, indicando la importancia de las mismas para un estudio relevante. João Batista Ribeiro Santos y Larissa Dantas Camargo Mello, en una 
investigación realizada en coautoría, presentan una nueva propuesta de lectura del Libro de Jonás, basada en el itinerario geográfico del mapa mental elaborado por los narradores y el género de la ficción en la profecía. Silas Klein Cardoso, nos presenta una exégesis iconográfica que utiliza trazos visuales de la antigua Palestina/Israel para iluminar términos, textos y conceptos bíblicos. En su texto presenta, su definición, desarrollos históricos, conceptos y métodos principales.

En el segundo bloque de textos, veremos más de cerca los temas relacionados con la dinámica hermenéutica.

Suely Xavier dos Santos nos dice que en la búsqueda de significados y reinterpretaciones, es necesario revisar los métodos de interpretación así como ampliar el diálogo con las ciencias de la modernidad. Nelson Maria Brechó da Silva, presenta la hermenéutica contemporánea de Gadamer a partir de la hipótesis de la lingüística como comprensión dialógica. Dialógica que implica la fusión de horizontes buscando analizar los efectos de los textos sagrados en tu comunidad.

Denilson Silva Matos, por un lado, Carlos Eduardo Mattos, por outro, aportan dos artículos que abordan un mismo género: el apocalíptico. En el primero, Denilson aborda el tema de la "metaforización de la mujer" en la escritura canónica de Apocalipse de João y, en el outro, Carlos Eduardo nos presenta un ejercicio de análisis literario a partir de la escritura extracanónica titulado Apocalipse de Pedro. Su objetivo es presentarnos una lectura, dentro de la propuesta de una red textual, que ayudó a la construcción del imaginario religioso del cristianismo primitivo.

Un tercer bloque de textos dialoga con el mundo social del texto bíblico en la perspectiva de repensar el techo y repensar las relaciones de los grupos productores de estos textos con su entorno.

Sílvio Cezar José Pereira Gomes, busca identificar quiénes eran los gentiles en la comunidad primitiva y cómo podrían ser identificados. Sus percepciones se dan a través de Hechos de los Apóstoles y la tradición oral rabínica. Danielle Lucy Bósio Frederico, que mira a las primeras comunidades cristianas desde la hermenéutica de los espacios, revisitando los espacios del mundo antiguo e indicando diversas posibilidades. Paulo Roberto Garcia dialoga con los instrumentales de la historia de la acusación para reconstruir un momento de una comunidad cristiana a partir del capítulo 21 del Evangelio de Juan.

Todos los autores, al revisar temas, textos y percepciones, nos aportan nuevas perspectivas que indican múltiples posibilidades de interpretación. Estas encuestas señalan la importancia del constante movimiento hermenéu- 
tico presente en una sociedad cada vez más plural, que al plantear nuevas preguntas ha encontrado nuevas respuestas, que iluminan y animan a realizar cada vez más investigaciones.

¡Una gran lectura!

\author{
Danielle Lucy Bósio Frederico \\ Universidade Metodista de São Paulo \\ Doutora em Ciências da Religião pela \\ Universidade Metodista de São Paulo (Umesp) \\ danielle.frederico@metodista.br
}

Paulo Roberto Garcia Universidade Metodista de São Paulo Doutor em Ciências da Religião pela Universidade Metodista de São Paulo (Umesp) paulo.garcia@metodista.br 